\title{
Metastasis: other side of the coin
}

\author{
Aftab Ahmad $^{1,2 *}$ and Shoji Komai ${ }^{2}$ \\ ${ }^{1}$ National Academy of Young Scientists (NAYS) Pakistan, Lahore, Pakistan, ${ }^{2}$ Graduate School of Biological Sciences, Nara \\ Institute of Science and Technology (NAIST), Ikoma, Japan
}

Keywords: regression, immune system, nervous system, dilution, proliferation

Metastasis is a leading cause of poor prognosis and cancer death worldwide and according to reports, metastasis results in almost $90 \%$ cancer-related deaths (1). The early detection of cancer and better understanding of cancer metastasis can be incredibly helpful in management of disease (2).

Recently, there is a great advancement in metastasis-related research but yet prognosis remains extremely poor. Metastasis is a very complex process, which is mainly through four steps: (i) departure of cells from the primary tumor, (ii) movement and survival of cancerous cells in circulator system, (iii) attachment of cells with the target organ through breaching of endothelial and basement membrane, and (iv) formation of metastatic cells colony in target organ (3). There are many players who are involved in these steps including nervous system, microenvironment, inflammation, immune system, and bone marrow (4-6). Among all these factors, nervous and immune system play an important role, directly or indirectly (7).

Angiogenesis is very important for metastasis (8) and for angiogenesis; vascular endothelial growth factor (VEGF) plays an important role. According to the reports, the level of VEGF increases in chronic stress, which result in vascularization and lead to metastasis $(9,10)$. In addition, under chronic stress, the sympathetic nervous system (SNS) also activated, which release neurotransmitters and these neurotransmitters, such as norephedrine, dopamine, and bradykinin, induce or suppress VEGF expression $(11,12)$.

Other neuron-related factors also play an important role in tumor angiogenesis like neuropilins

Edited by:

John March,

Cornell University, USA

Reviewed by:

Riffat Mehboob,

King Edward Medical University,

Pakistan

*Correspondence:

Aftab Ahmad

aftabac@yahoo.com,

aftab@bs.naist.jp

Specialty section:

This article was submitted to Molecular and Cellular Oncology, a section of the journal

Frontiers in Oncology

Received: 24 March 2015

Accepted: 06 July 2015

Published: 04 August 2015

Citation:

Ahmad A and Komai S (2015)

Metastasis: other side of the coin.

Front. Oncol. 5:163.

doi: 10.3389/fonc.2015.00163 and semaphorins. These factors can promote or inhibit the angiogenesis process (13-15). Moreover, calcitonin gene-related peptide (CGRP), which is a neuropeptide, can also facilitate angiogenesis in tumor (16). Another neuropeptide, neuropeptide Y (NPY), is also involved in angiogenesis by regulating the expression of VEGF (17). Overall, nervous system modulates angiogenesis, which further lead to metastasis.

According to a recent study by Magnon et al. (18), tumor sections of mouse contained tumor infiltrating sympathetic and parasympathetic nerves and along with mature there were also some newly formed nerves. In the same study, when sympathetic nerve were ablated surgically or chemically, the growth of tumor was prevented in mice and similar results were also obtained when same nerve were ablated in genetic model of prostate cancer. In the later case, only cancer was prevented in young mice but no effect was observed in adults, which indicate that SNS is important for early tumorigenesis (18). The mechanism of tumor growth by SNS was also revealed in this study and that was through $\beta 2$-adrenergic receptor (ADRB2). ADRB2 has been shown to be expressed on tumor cells, while SNS transmits stress signals, which activate these receptors and result in tumor growth.

Some recent investigations have challenged the canonical theory of tumor metastasis and according to new theory, the cancerous cells have an innate property of metastasis and malignant cells can disseminate and release into circulation much earlier than previously anticipated (19). In addition, the non-neoplastic host cells in tumor microenvironment including neuronal cells also play a significant role in regulation of metastasis (18).

Metastasis is always said to be a bad process and usually it is considered as "death statement" for patient but can it be beneficial? According to a study by Peeters et al. (20), primary tumor may inhibit the growth of metastasized tumor, as the vascular density in human liver metastatic cancer 
increased after primary tumor resection from colon (20). According to this study, primary tumor blocks the growth of metastasized tumor by blocking angiogenesis process. In this way, the stress at primary tumor place is reduced by release of cells and primary tumor further helps in blocking the growth of metastatic tumor.

There are several cases where there was spontaneous regression of primary tumors and especially renal cell carcinoma (RCC). Like metastasis, the process of regression is also very complex and many genetics, epigenetic, immunological, and neurological factors are involved, which act through apoptosis, immune system activation, tumor microenvironment, inhibition of metalloproteinases, lack of angiogenesis, and absence of specific proteins. All these factors act together and result in tumor regression (21, 22). In addition, there are also several documented cases of spontaneous regression of metastatic tumor, but what mechanism is involved in this regression is still unknown and needs further investigations (23-25).

According to different reports, all type of tumors can regress spontaneously, although, some cancers regress more frequently than others. In addition, not only malignant but regression was also observed in benign tumors [Sante Basso (26)]. Moreover, the dilution in numbers of cancer cells in the blood also stimulates the immune system and result in regression. It was observed that metastasis was less frequent in renal carcinoma patients who undergo hemodialysis, which indicates that, the number of cancer cells reduced due to their blockage using dialytic membrane. Cancer cells are slowly released in circulation from primary tumor, so more accessible to immune cells; and hence, immune system recognize these cells in better way and prepare the body to fight against cancer, which could be hard in primary solid tumor [S Basso (27); Sante Basso (26)].

The primary tumor normally escape the anti-tumor response of the immune system and many factors play an important role for this escape, especially tumor microenvironment and immune system exclusion and ignorance $(28,29)$. It indicates that the access of immune cells to primary tumor is less. In addition, if the patient are administered with autologous cancer cells, they enhance the anti-tumor immunity in patients, especially when the cells were engineered to secrete granulocyte-macrophage colony stimulating factor (GM-CSF), which indicate that circulating cancer cells are better recognized by immune cells and they mount anti-tumor response $(30,31)$, so metastasis make the tumor cells more accessible to immune cells.

According to reports, the process of regression is more common in metastasized tumor compared to primary tumors [Sante Basso (26)]. When cancer cells move to new location, the microenvironment at new location also affect the cancer cells and block its proliferation. In addition, microenvironment also lock the cancer cells, which reduce their number in circulation and so help in mounting the immune response due to dilution factor of

\section{References}

1. Spano D, Heck C, De Antonellis P, Christofori G, Zollo M. Molecular networks that regulate cancer metastasis. Semin Cancer Biol (2012) 22(3):234-49. doi:10. 1016/j.semcancer.2012.03.006

2. Chaffer CL, Weinberg RA. A perspective on cancer cell metastasis. Science (2011) 331(6024):1559-64. doi:10.1126/science.1203543

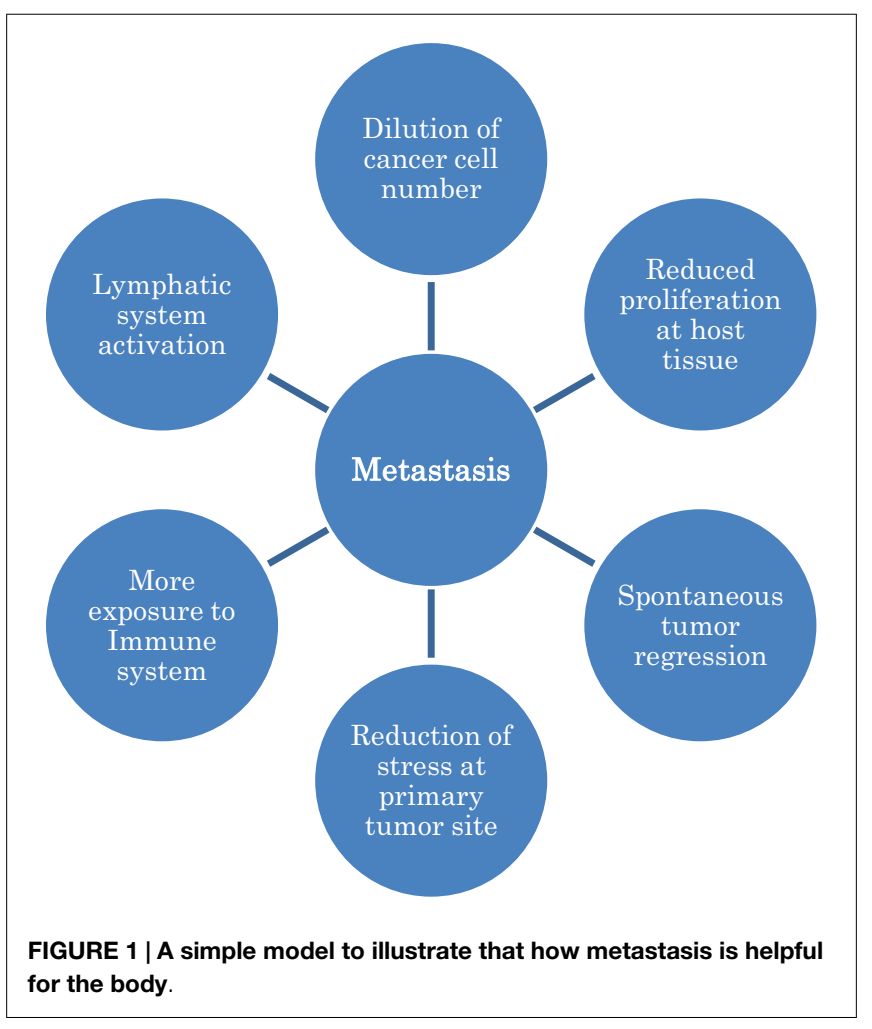

cancerous cells. The cells releases from primary tumor are also not always form a tumor at new location. Moreover, after release from the primary tumor, certain tumor cells end up into lymph nodes, which are highly active sites of immune system, so these cancer cells are not only blocked but also greatly stimulate the immune system, which result in spontaneous regression of cancer. Several such cases of spontaneous regression of lymph node metastasis have been reported (32). How metastasis is beneficial for the body is simply illustrated in Figure 1.

On the basis of above discussion, it can be concluded that although metastasis is not good for treatment of cancer, as it is hard to treat cancer when it is not localized but there is also need to re-think about metastasis process, as it is a body's response to target the diseases and mount an immune response against cancerous cells. The nervous system modulate and facilitate metastasis to reduce the stress of cancer mass at its primary location and better expose cancer cells, so the immune system could recognize them and target these cells not only at its primary location but also at metastatic locations. Just like the old theory of release of cancer cells from primary tumor is changed, we have to re-think about metastatic process as metastasis is also helpful for the body in number of ways (Figure 1). The new theory can also give us many potential new targets and ways to target cancer.

3. Gupta GP, Massagué J. Cancer metastasis: building a framework. Cell (2006) 127(4):679-95. doi:10.1016/j.cell.2006.11.001

4. Calorini L, Peppicelli S, Bianchini F. Extracellular acidity as favouring factor of tumor progression and metastatic dissemination. Exp Oncol (2012) 34(2):79-84.

5. Calorini L, Bianchini F. Environmental control of invasiveness and metastatic dissemination of tumor cells: the role of tumor cell-host 
cell interactions. Cell Commun Signal (2010) 8:24. doi:10.1186/1478811X-8-24

6. De Visser KE, Eichten A, Coussens LM. Paradoxical roles of the immune system during cancer development. Nat Rev Cancer (2006) 6(1):24-37. doi:10.1038/ nrc1782

7. Li S, Sun Y, Gao D. Role of the nervous system in cancer metastasis. Oncol Lett (2013) 5(4):1101-11. doi:10.3892/ol.2013.1168

8. Weis SM, Cheresh DA. Tumor angiogenesis: molecular pathways and therapeutic targets. Nat Med (2011) 17(11):1359-70. doi:10.1038/nm.2537

9. Lutgendorf SK, Cole S, Costanzo E, Bradley S, Coffin J, Jabbari S, et al. Stress-related mediators stimulate vascular endothelial growth factor secretion by two ovarian cancer cell lines. Clin Cancer Res (2003) 9(12): 4514-21.

10. Thaker PH, Han LY, Kamat AA, Arevalo JM, Takahashi R, Lu C, et al. Chronic stress promotes tumor growth and angiogenesis in a mouse model of ovarian carcinoma. Nat Med (2006) 12(8):939-44. doi:10.1038/nm1447

11. Ishihara K, Kamata M, Hayashi I, Yamashina S, Majima M. Roles of bradykinin in vascular permeability and angiogenesis in solid tumor. Int Immunopharmacol (2002) 2(4):499-509. doi:10.1016/S1567-5769(01)00193-X

12. Park SY, Kang JH, Jeong KJ, Lee J, Han JW, Choi WS, et al. Norepinephrine induces VEGF expression and angiogenesis by a hypoxia-inducible factor- $1 \alpha$ protein-dependent mechanism. Int J Cancer (2011) 128(10):2306-16. doi:10. 1002/ijc. 25589

13. Basile JR, Castilho RM, Williams VP, Gutkind JS. Semaphorin 4D provides a link between axon guidance processes and tumor-induced angiogenesis. Proc Natl Acad Sci U S A (2006) 103(24):9017-22. doi:10.1073/pnas. 0508825103

14. Chen C, Li M, Chai H, Yang H, Fisher WE, Yao Q. Roles of neuropilins in neuronal development, angiogenesis, and cancers. World J Surg (2005) 29(3):271-5. doi:10.1007/s00268-004-7818-1

15. Sakurai A, Doçi CL, Doci C, Gutkind JS. Semaphorin signaling in angiogenesis, lymphangiogenesis and cancer. Cell Res (2012) 22(1):23-32. doi:10.1038/cr. 2011.198

16. Toda M, Suzuki T, Hosono K, Hayashi I, Hashiba S, Onuma Y, et al. Neuronal system-dependent facilitation of tumor angiogenesis and tumor growth by calcitonin gene-related peptide. Proc Natl Acad Sci U S A (2008) 105(36):13550-5. doi:10.1073/pnas.0800767105

17. Lee EW, Michalkiewicz M, Kitlinska J, Kalezic I, Switalska H, Yoo P, et al. Neuropeptide $\mathrm{Y}$ induces ischemic angiogenesis and restores function of ischemic skeletal muscles. J Clin Invest (2003) 111(12):1853-62. doi:10.1172/ JCI16929

18. Magnon C, Hall SJ, Lin J, Xue X, Gerber L, Freedland SJ, et al. Autonomic nerve development contributes to prostate cancer progression. Science (2013) 341(6142):1236361. doi:10.1126/science.1236361

19. Coghlin C, Murray GI. Current and emerging concepts in tumour metastasis. J Pathol (2010) 222(1):1-15. doi:10.1002/path.2727

20. Peeters CF, de Waal RM, Wobbes T, Westphal JR, Ruers TJ. Outgrowth of human liver metastases after resection of the primary colorectal tumor: a shift in the balance between apoptosis and proliferation. Int J Cancer (2006) 119(6):1249-53. doi:10.1002/ijc.21928
21. Janiszewska AD, Poletajew S, Wasiutyński A. Spontaneous regression of renal cell carcinoma. Contemp Oncol (Pozn) (2013) 17(2):123-7. doi:10.5114/wo. 2013.34613

22. Jawanda GG, Drachenberg D. Spontaneous regression of biopsy proven primary renal cell carcinoma: a case study. Can Urol Assoc (2012) 6(5):E203-5. doi:10. 5489/cuaj.11035

23. Lekanidi K, Vlachou PA, Morgan B, Vasanthan S. Spontaneous regression of metastatic renal cell carcinoma: case report. J Med Case Reports (2007) 1:89. doi:10.1186/1752-1947-1-89

24. Lim R, Tan PH, Cheng C, Agasthian T, Tan HL, Teh BT, et al. A unique case of spontaneous regression of metastatic papillary renal cell carcinoma: a case report. Cases J (2009) 2(1):7769. doi:10.4076/1757-1626-2-7769

25. Lokich J. Spontaneous regression of metastatic renal cancer. Case report and literature review. Am J Clin Oncol (1997) 20(4):416-8. doi:10.1097/ 00000421-199708000-00020

26. Ricci SB, Cerchiari U. Spontaneous regression of malignant tumors: importance of the immune system and other factors (Review). Oncol Lett (2010) 1(6):941-5. doi:10.3892/ol.2010.176

27. Ricci SB. Dialysis membrane and diffusion of metastatic cancer cells. Clin Nephrol (2007) 68(6):354-6. doi:10.5414/CNP68354

28. Gajewski TF, Schreiber H, Fu Y-X. Innate and adaptive immune cells in the tumor microenvironment. Nat Immunol (2013) 14(10):1014-22. doi:10.1038/ ni. 2703

29. Igney $\mathrm{FH}, \mathrm{Krammer} \mathrm{PH}$. Immune escape of tumors: apoptosis resistance and tumor counterattack. J Leukoc Biol (2002) 71(6):907-20.

30. Jaffee EM, Hruban RH, Biedrzycki B, Laheru D, Schepers K, Sauter PR, et al. Novel allogeneic granulocyte-macrophage colony-stimulating factor-secreting tumor vaccine for pancreatic cancer: a phase $\mathrm{i}$ trial of safety and immune activation. J Clin Oncol (2001) 19(1):145-56.

31. Salgia R, Lynch T, Skarin A, Lucca J, Lynch C, Jung K, et al. Vaccination with irradiated autologous tumor cells engineered to secrete granulocytemacrophage colony-stimulating factor augments antitumor immunity in some patients with metastatic non-small-cell lung carcinoma. J Clin Oncol (2003) 21(4):624-30. doi:10.1200/JCO.2003.03.091

32. Kurita M, Hirano K, Ebihara S, Takushima A, Harii K, Fujino T, et al. Spontaneous regression of cervical lymph node metastasis in a patient with mesopharyngeal squamous cell carcinoma of the tongue: possible association between apoptosis and tumor regression. Int J Clin Oncol (2007) 12(6):448-54. doi:10. 1007/s10147-007-0711-9

Conflict of Interest Statement: The authors declare that the research was conducted in the absence of any commercial or financial relationships that could be construed as a potential conflict of interest.

Copyright (c) 2015 Ahmad and Komai. This is an open-access article distributed under the terms of the Creative Commons Attribution License (CC BY). The use, distribution or reproduction in other forums is permitted, provided the original author(s) or licensor are credited and that the original publication in this journal is cited, in accordance with accepted academic practice. No use, distribution or reproduction is permitted which does not comply with these terms. 